\title{
Evaluating the Effect of Process Parameters on FSP of Al5083 Alloy Using ANSYS
}

\author{
Shourya Sahdev, Himanshu Kumar, Ravi Butola*, Ranganath M. Singari \\ Department of Mechanical Engineering, Delhi Technological University, Delhi 110042, India
}

Corresponding Author Email: ravibutola33855@gmail.com

https://doi.org/10.18280/acsm.450203

Received: 4 January 2021

Accepted: 11 March 2021

\section{Keywords:}

friction stir processing, process parameters, aluminium 5083, numerical modelling

\begin{abstract}
Friction stir processing (FSP), compared to other solid-state processing methods, is a one-step process that attains refinement and homogeneity in its Microstructure. The complex configuration of various kinds of welds in FSP and their 3-D (threedimensional) nature makes it tough to develop an overall system of ruling equations for theoretically analysing the functioning of the friction stir processed materials. The experimental trials are usually expensive and time-consuming. These hurdles can be overcome often by doing numerical analysis. The mechanical and microstructural characteristics of the Stir-Zone can be precisely supervised by enhancing the parameters of tool design, material properties, parameters of friction stir processing, and active heating and cooling. In this study, the significance of process parameters during FSP of Aluminium 5083 and the role of numerical analysis using ANSYS Workbench in the prediction of material behaviour have been discussed.
\end{abstract}

\section{INTRODUCTION}

The Welding Institute UK in 1991 invented a solid-state metal welding process Friction Stir Welding (FSW) [1]. In this method, a non-depleting rotating tool (of a material tougher than the workpiece material) is plunged into the abutting edges of the workpiece, followed by the translation of the rotating tool relative to the workpiece to form a weld next to the joint line as shown in (Figure 1). This consequently results in the Severe Plastic Deformation (SPD) and dynamic recrystallization in the weld region at elevated temperatures lower than the MP (melting point) of the workpiece material $[2,3]$. FSW is widely adopted for joining hard-to-weld metallic alloys in different industry fields and is considered to be more effective than conventional fusion welding $[4,5]$. Friction Stir Welding can weld aluminium alloys or different metal alloys which are reckoned to be non-weldable by regular methods because of porosity in the fusion zone and poor microstructural solidification. Some alloys can also be resistant welded but it is considered to be costly because of surface preparation hence it is not a viable option. Also, the loss in mechanical characteristics of the base material is sufficiently lower than that obtained by conventional methods. In contrast to fusion welding, FSW has reduced deformation and gives rise to fine equiaxed recrystallized grains and good mechanical traits in the welded workpiece. FSW is considered to be an environment-friendly process as smoke, arc glares, and fumes are not produced during the process [6]. Microstructural evolution during the FSP changes the grain boundary character, granular size, texture and breakup and redistribution of dispersoids. FSW leads to the formation of distinct microstructural zones and each zone imparts different mechanical properties. The various zones formed during the FSW process are Thermo-mechanically Affected Zone (TMAZ), Heat Affected Zone (HAZ) and Stir Zone (SZ) [2, 7, 8]. The stir zone consists of fully recrystallized fine-grained material and corresponds to the position of the tool pin during the joining process. The TMAZ is created on either part of the $\mathrm{SZ}$ and the temperature, microstructural changes and strain are lower in this area concerning the SZ. Proximate to the THAZ, the HAZ is created. HAZ is common to all joining techniques and corresponds to the area subjected to a thermal cycle but the material in this region is not deformed during the welding process. Besides, the direction of rotation of the tool also affects the microstructural properties of the workpiece. The forward-moving side is the region in which the course of tool rotation and the course of the translational tool motion is the same. The solid material commences altering into a semi-solid one in this region. The semi-solid material retreated and cooled on the retreating side. The direction of translational motion of the tool is opposite to the direction of tool rotation on this side. The mechanical features of the SZ are improved in comparison to the base metal due to the uniformly distributed particles and the homogenous microstructure present in the stir zone [9]. A better surface finish was observed in the SZ in comparison to the base metal. FSW led to the removal of surface defects like voids and cracks in the stir zone, the hardness values in the SZ were noted to be more uniform in comparison to the base metal and the ultimate tensile strength and yield strength also showed an improved value in the SZ. The process parameters (such as tool traverse speed, plunge depth, tool rotational speed, and tool tilt angle) considered during the process highly influence microstructural properties and the temperature values recorded in the SZ [10].

Considering the influence of FSW on the microstructural characteristics of the workpiece and the corresponding refinement in the mechanical characteristics of the SZ, a new metal processing mechanism established on the elemental fundamentals of the FSW process was developed named the Friction Stir Processing (FSP) [11]. FSP is a very effective solid-state processing method that is used to provide a localized modification and alter the microstructural properties 
of metallic materials. FSP is widely used for surface applications as it leads to an improvement in tensile strength and hardness of the material. It also refines the grain structure and thus improving the mechanical and wear properties of the metal [12-14].



Figure 1. Schematic diagram of FSW [15]

$\mathrm{Al}-5083$ (Al-Mg alloy) has been widely used in aerospace and transportation industries because of its good formability, high strength to weight ratio, excellent corrosion resistance and low density. As one of the solution-strengthened alloys, Al-5083 can only be strengthened by work hardening and micro alloying [15]. Therefore, FSP is a notable method used in the fabrication of Al-5083 for various surface applications. Though there is a notable amount of literature on the development of surface composites of Al-5083, there is a lack of literature on the role of numerical simulation in the material development process. Based on the above issues, two aspects need to be discussed in depth: the role of computational simulation in the material development process and the effect of various parameters on the workpiece material.

The objectives of this particular investigation are to analyse the experimental data collected corresponding to processing parameter values, to determine a relationship, to obtain the desired properties of the material. In this work, a thirddimensional (3-D) thermo-mechanical framework of the FSW of Aluminium 5083, an aluminium alloy is developed using the help of the Finite Element Method with ANSYS 18.1 software to comprehend and validate the role of process parameters in FSP. Four sets of process parameters were selected and a parametric analysis was conducted to ascertain the influence of speed of rotation, the translational speed, and plunge depth on the thermal field around the Aluminium 5083 alloy during the FSW process.

\section{FRICTION STIR PROCESSING}

Mishra et al. developed a new metal processing technique based on the FSW process in 2002 [16]. It was initially proposed as a new technique for developing surface composites that were effective in increasing the microhardness of the material. It is a bulk processing technique. FSP has found various other applications such as to improve the malleability of materials, repair of casting defects, development of surface composite materials, modification of welded joints, etc. [17]. FSP is a comparatively new method of Super Plastic Deformation (SPD) in contrast to the other methods of SDP such as multi-directional forging (MAF), accumulative roll-bonding (ARB), high-pressure torsion (HPT), and equal channel angular pressing (ECAP) [18]. It is also faster than other solid-state processing methods. Z.Y. Ma et al. produced $7075 \mathrm{Al}$ alloy plates that were subjected to Super Plastic Deformation using FSP [19]. 7075Al alloys with a high-quality grain length were produced and led to substantially better superplastic ductility, decrease in flow stress, decreased optimum temperature, and a change to greater optimum strain rates. FSP has successfully processed materials such as AA2519, AA7075, AA5083 aluminium alloys, Stainless steel, AZ61 magnesium alloy, and nickelaluminium bronze. FSP is considered to have several advantages as compared to the other SPD processes that have been stated as follows [20]:

(1) FSP is more efficient in homogenizing powder metallurgy processed aluminium alloys.

(2) It can modify the microstructure of the metal matrix composites and thus the joint area impart great metallurgical properties.

(3) Helps to eliminate casting defects and is used for property enhancement in casting $\mathrm{Al}$ alloys.

(4) It is able to break up or dissolve the second phase particles which bring about a considerable improvement in properties.

(5) No surface cleaning is required before the process.

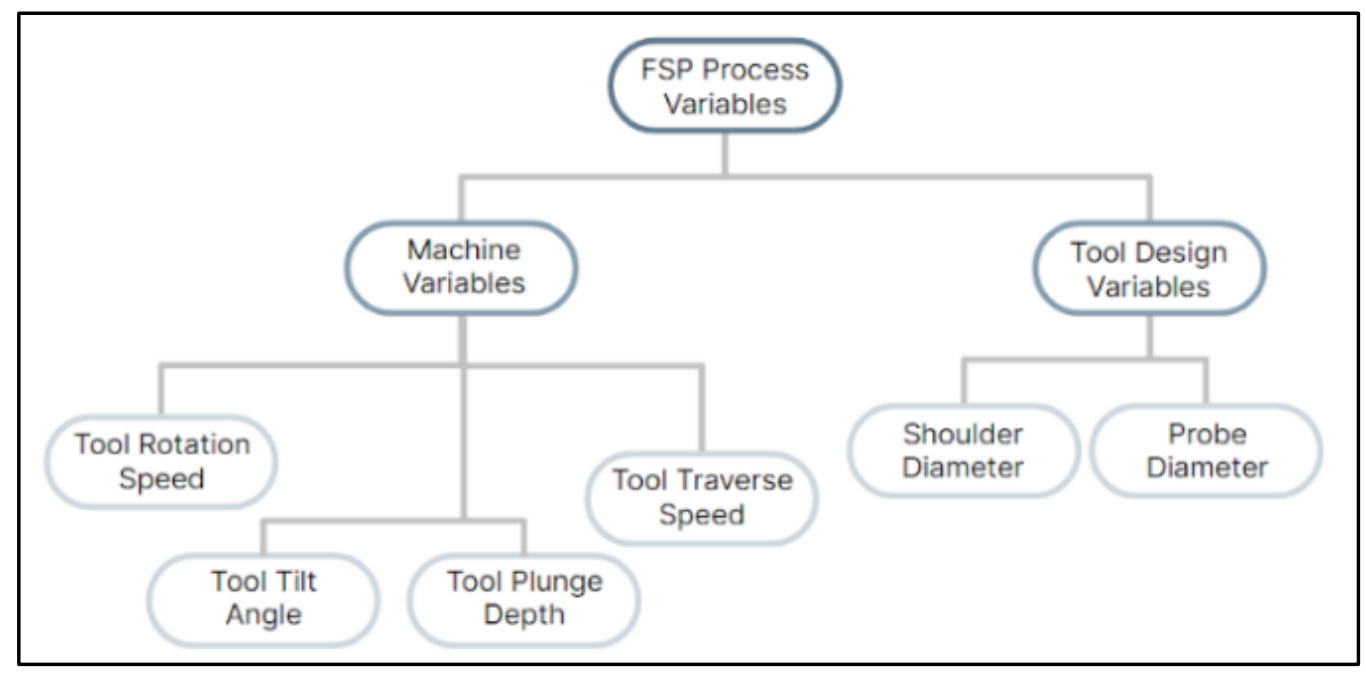

Figure 2. Effect of FSP process variables 
The consequent microstructural change in metallic materials after FSP are highly influenced by various factors which include processing parameters, welding parameters, joint design, and tool geometry (Figure 2). Despite the fact that friction stir processing is a noble technique it is still not sufficiently mature for solving practical applications [21]. Therefore, mathematical physics models are used for parameter optimisation of the process and hence helps us formulate a suitable process. Some recent studies have suggested that the thermal fields during the FS process have a critical role in determining the resulting material properties and microstructure of the material [22]. Some of the important aspects of FSP have been discussed below.

\subsection{Processing parameters}

The tool geometry and welding parameters put a massive effect on the distribution of temperature and material flow behaviour and thus causing a change in the microstructure of the material [23]. It is of very much importance to find the ideal values for process parameters as they control the biggest component of the heating source. Low heat input causes an increase in the grain refinement, but a high heat input is needed to plasticise or soften up the material. Smaller grain size is observed, while the defects increase for a low value of rotational speed and a high value of traverse speed and vice versa [24]. Therefore, traverse and rotational speed needs to be optimised to attain a SZ with no defects and reduced grain size. Some of the major processing parameters have been discussed below.

\subsubsection{Tool rotation rate}

More dissolution of soluble particles and greater fragmentation of insoluble particles have been observed for an increment in tool rotation rates [25]. An increment in tool rotation rate improves the resultant grain size and leads to a substantial rise in the temperature of the stir zone. Tool rotation speed is also important for the stirring and unification of the workpiece material. Direction of tool rotation, affects the microstructural evolution of the material [26]. The microstructure of the material is not found to be symmetric w.r.t. the traverse length after a single pass of the tool [27], hence multiple passes of the tool are preferred as they lead to a more homogenous processed region.

\subsubsection{Tool traverse speed}

The tool traverse speed is accountable for moving the material from the initial to the rear portion of the workpiece. A low tool traverse speed causes a rise in the grain size of the FS processed zone. It has a negligible effect on the tool wear. An increase in traverse speed of the tool increases the microhardness of FS processed surface composites because of the higher distribution of reinforcement particles [28].

\subsubsection{Tilt angle}

The FSP tool tilt angle makes sure that the tool shoulder holds the stirred material and transfers it towards the back of the tool shoulder. A rise in the tool tilt angle brings about an increase in processing temperature [29]. A low value of the tilt angle is responsible for the defects in the processed zone while a higher value of the tilt angle increases the particle size and grain size of the processed zone [30].

\subsubsection{Tool insertion depth}

The tool insertion depth is responsible for maintaining contact with the molten metal and therefore ensure the production of a defect-free processed zone. It also helps to reduce the tool wear. But a high insertion depth can lead to an increase in the width of the plasticised region and a decrease in the hardness of the processed region [31]. An increase in tool insertion depth also leads to an increase in an excessive flash and hence a concave processed-zone is produced in such cases.

\subsection{Microstructural evolution}

FSP leads to refinement of grains due to dynamic recrystallization and therefore the enhancement of some mechanical properties [32]. FSP results in a significant improvement in microstructural refinement, an increase in density, and homogeneity of the processed zone. Some studies show that the fatigue strength decreases with decrease in ductility, and ultimate tensile strength but there is an improvement in the fatigue life of the processed material in comparison to the base metal [33]. Micrographs showed that differences in the size of inter-metallic bonding were found in FS processed materials which indicated that fracture is initiated due to the breaking of the brittle intermetallic bonding. Due to heterogeneous plastic deformation, the evolution of various grain particles may be different during FS Process [34]. No variation in structure is observed even after multiple passes, but it leads to the homogenisation of the microstructure. FSP is majorly used for the introduction of certain reinforcement particles in a material leading to the production of a surface composite that results in an improvement in properties of the material. According to the latest research, the process parameters contribute a lot towards microhardness of surface composites of FS processed materials, confirming that the most influential process parameters are rotational speed, reinforcement type and tool profile [35]. It was concluded that $\mathrm{B}_{4} \mathrm{C}$ should be considered as a better reinforcement material in comparison to $\mathrm{SiC}$ and RHA for improving the microhardness value of the composites, the value increased by 1.5 to 1.6 times from that of the workpiece material. The effects of FSP on cast aluminium alloy were studied by $\mathrm{Ma}$ et al. [36]. It was concluded that FSP led to the fine break-up and redistribution of constituent particles thus homogenizing the cast microstructure and completely eliminating porosity. For homogenising the particle distribution in surface composites, FPS can be effectively used [37].

\subsection{Surface composites}

FSP is a versatile process used for the production of surface composites [38]. Engineering applications that involve surface interactions, Surface composites are ideal materials for those applications. The various types of surface composites under development are in-situ composites, micro composites, hybrid composites, and nano-composites [39-42]. Surface composites are used to improve surface properties like abrasion resistance, corrosion resistance, hardness, fatigue life, formability, strength, and ductility [43]. Al, Mg, Steel, and Ti-based alloys are used for surface composites. Butola et al. [44] successfully fabricated the SAM (Self-Assembled Monolayer) technique of $\mathrm{Al}-\mathrm{B}_{4} \mathrm{C}$ nano-ceramic surface composite by implementing FSP. The mechanical properties of fabricated nano-ceramic surface composites on evaluation after one pass exhibited 
higher hardness, ultimate tensile strength, and finer grain structure in comparison to the base metal (BM). The fabrication of AA7075-T6 reinforced with $\mathrm{SiC}$ and Aloe vera ash, using FSP showed an improvement in wear and mechanical properties of all fabricated composite in comparison to the base metal [45]. Microhardness improved with the introduction of reinforcement.

\section{MATERIAL PROPERTIES}

H13 tool steel material was preferred as the tool material for the present study as it is recommended for the manufacturing of friction stir welding [46]. The material (Al 5083) was selected for the workpiece. Aluminium 5083 is highly resistant to attack by industrial chemical environments and seawater. It is also known for remarkable performance in extreme environments. The FSP of Al5083 is highly desirable to introduce surface modification and surface hardening and it is considered to have potential applications for manufacturing hybrid alloys. Vaira Vignesh et al. compared the intergranular corrosion of the Al5083 specimen with that of its FS Processed specimen [47] by applying the nitric acid mass loss test. The intergranular corrosion of the FS Processed specimen was lower than the base metal. R. Vaira Vignesh et al. also concluded that the FSPed specimens of A15083 have better wear resistance as compared to the base metal. A. Yazdipour et al. studied the effect of cooling rate on the FSPed specimens of Al5083 [48]. It was observed that the cooling rate affects the final grain size and the grain growth of the metal. There is no effect of multiple passes on the microstructural and mechanical properties of the stir zone of the FSPed specimens of Al5083 [49]. Recent studies have shown that the inclusion of vibration during the FSP process leads to an improvement in mechanical and microstructural properties such as grain refinement, strength, microhardness and formability of the FSPed specimens of Al5083 [50, 51].

\section{NUMERICAL ANALYSIS OF FSP}

A three-dimensional (3-D) thermomechanical model of the FSP of Aluminium 5083 is developed with the help of Finite Element Method using the ANSYS 18.1 software in order to understand and validate the role of process parameters in FSW. The ANSYS software was selected on the basis of its superiority in terms of simulating mechanical properties, temperature distributions, heat transfer, and deformation [52]. The mathematical model developed for the Friction Stir Processing helps in simulating the temperature and the stress values, that are generated in the heat-affected zone. The major process parameters that govern the value of thermomechanical stress generated during the motion of the tool are its plunge depth, translational speed, rotational speed, and tool angle.

\subsection{Finite Element Model (FEM) description}

The model was simulated using transient structural analysis in ANSYS Mechanical APDL and user-defined functions were implemented to account for an extra DOF for temperature. To deal with distortion of the mesh and high calculation time, features of the code that are built-in such as Augmented Lagrangian and mass scaling method were used. The workpiece dimensions were taken to be $100 \times 50 \times 5 \mathrm{~mm}$ and the tool diameter was taken to be $20 \mathrm{~mm}$ with a thickness of $5 \mathrm{~mm}$. The dwell time was taken to be 5 seconds. To study the effects of process parameters on the temperature distribution behaviour w.r.t displacement of the tool this model was used. The ANSYS model is shown in Figure 3 which depicts the direction of tool rotation, direction of tool translation and the constraints applied to the FEM model.

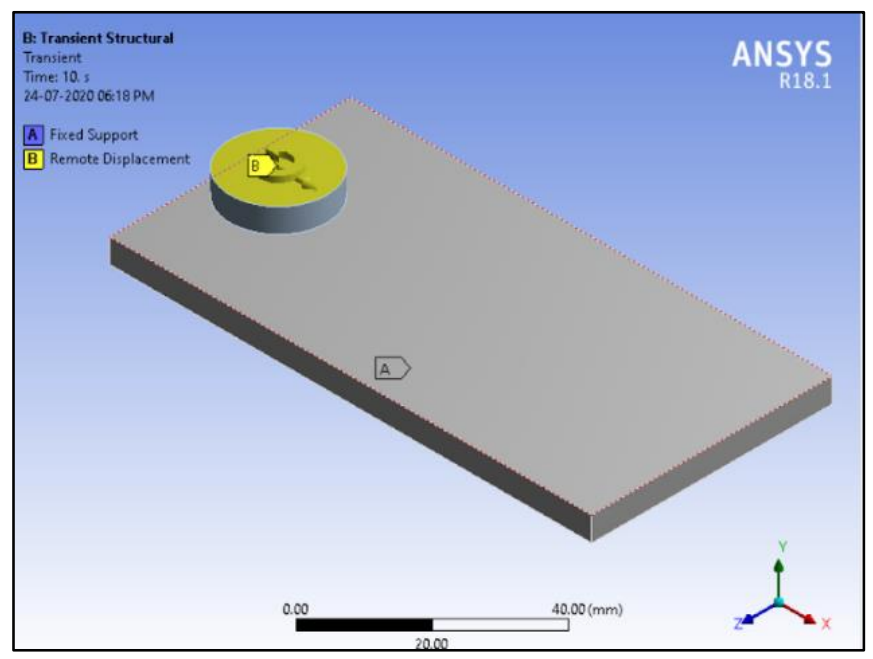

Figure 3. ANSYS model

\subsection{Mesh properties}

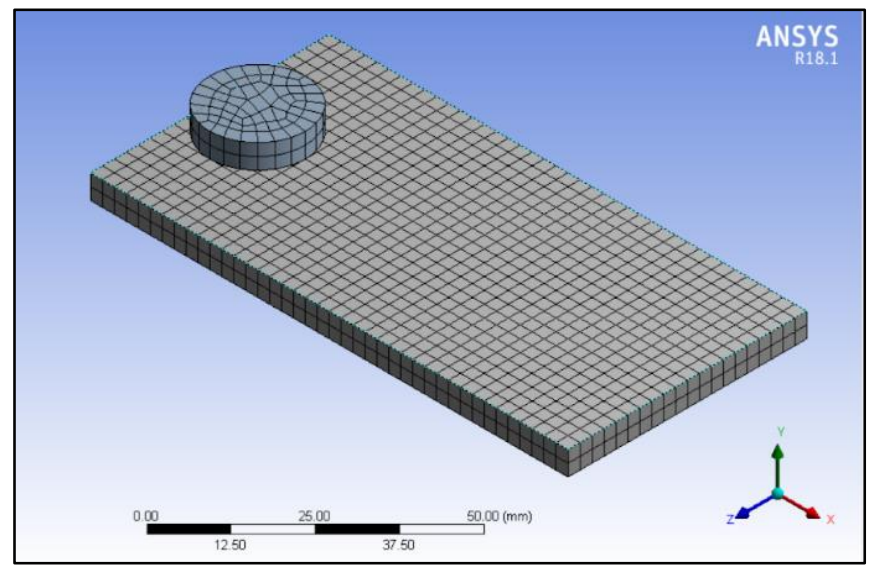

Figure 4. Meshed ANSYS FSP model

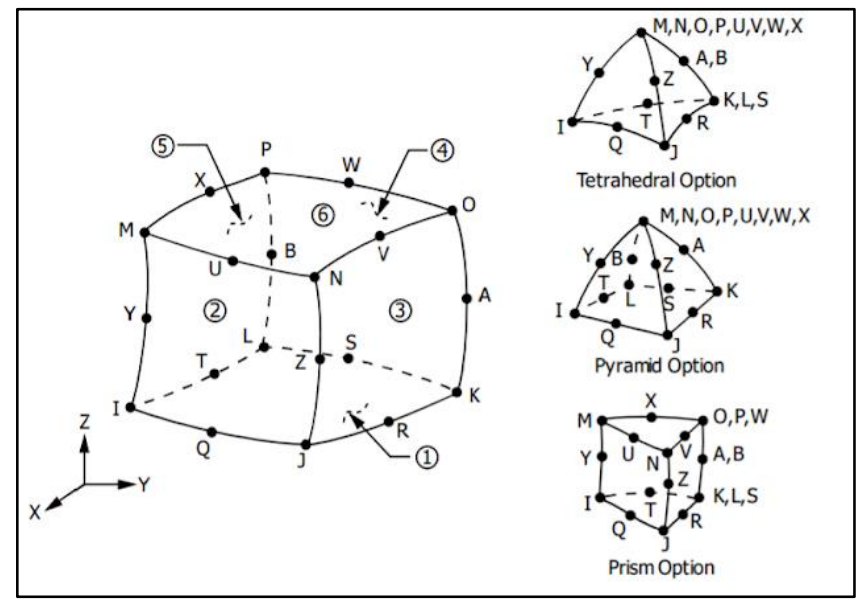

Figure 5. Types of Mesh in ANSYS 
The mesh size was selected to be $2.5 \mathrm{~mm}$ to ensure less computational time and maintain the result accuracy (Figure 4). The type of mesh used in this analysis was SOLID226 (Figure 5). SOLID226 is a 20-Node 3D Coupled-Field Solid that helps to enable an extra DOF of temperature for structural analysis at the contact surface, and thus account for the temperature change along with geometry. This type of mesh was selected because its structural capabilities include plasticity, elasticity, hyper elasticity, large strain, viscoelasticity, stress stiffening effects, viscoelasticity, creep, and large deflection.

\subsection{Experimental procedure}

Three steps namely preheating, plunging, and traversing were defined for simulation, and data was collected according to the process parameter values as presented in Table 1.

Table 1. Process parameter values

\begin{tabular}{cccc}
\hline $\begin{array}{c}\text { Experiment } \\
\text { No. }\end{array}$ & $\begin{array}{c}\text { Rotational } \\
\text { Speed }\end{array}$ & $\begin{array}{c}\text { Translational } \\
\text { Speed }\end{array}$ & $\begin{array}{c}\text { Plunge } \\
\text { Depth }\end{array}$ \\
\hline 1. & $200 \mathrm{rpm}$ & $60 \mathrm{~mm} / \mathrm{min}$ & 0.2 \\
2. & $500 \mathrm{rpm}$ & $60 \mathrm{~mm} / \mathrm{min}$ & 0.2 \\
3. & $200 \mathrm{rpm}$ & $40 \mathrm{~mm} / \mathrm{min}$ & 0.2 \\
4. & $200 \mathrm{rpm}$ & $60 \mathrm{~mm} / \mathrm{min}$ & 0.5 \\
\hline
\end{tabular}

\section{EFFECT OF PROCESS PARAMETERS}

A complex material movement and plastic deformation can be attained by FSW/FSP. Welding parameters, joint design and tool geometry exert a large impact on the material flow behaviour and temperature distribution. The resultant microstructure and material properties are dependent on the temperature in the SZ. A lower temperature in the SZ (stir zone) leads to an increase in grain size. But to plasticize the material adequate heat input is required. Therefore, the correct value of process parameters needs to be selected so that it can obtain the material with desired properties. The results of the experimental analysis 1 (Figure 6) were compared with the other three analysis to conclude the effect of change of a specific process parameter. The Figures 6-11 depicts the rise in temperature value of the workpiece during FSP. The colour contour chart helps to denote the temperature value associated with a specific colour. Hence, the colour schematic helps to predict and compare the temperature profile that will be obtained on performing FSP using the specific set of process parameters on Al-5083 alloy. The significance of the process parameters considered for this analysis have been discussed below:

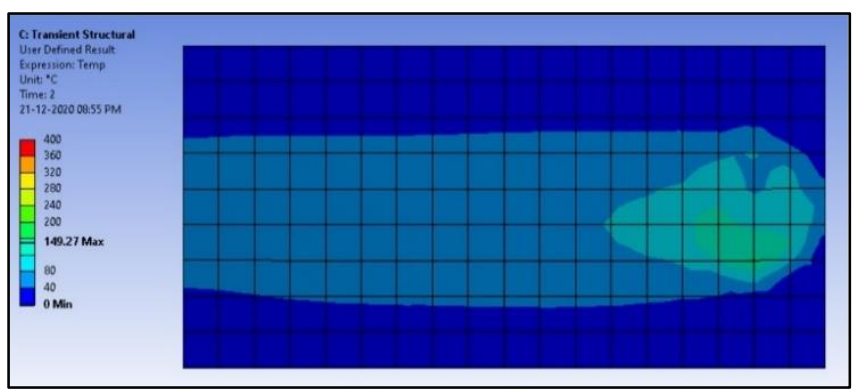

Figure 6. Experimental analysis 1 temperature results

\subsection{Rotational speed}

The rotation of the tool ends-up in mixing and stirring of material near the rotating pin. For higher the rotation of the tool, higher were the temperatures, due to an increased amount of frictional heating, which resulted in a more severe mixing and stirring of the material. A significant increase in temperature value was observed on increasing the rotational speed from 200rpm. The movement of the tool results in material being stirred and mixed around the spinning pin. Due to greater frictional heating and higher rates of tool rotation an increase in temperature and a more severe mixing and stirring of the given material is observed. A large increase in the temperature value was observed on increasing the rotational speed from 200rpm (Figure 6) to 500rpm (Figure 7). It also led to an increase in the overall heated area on the surface of the workpiece. A maximum temperature $=389.04^{\circ} \mathrm{C}$ was noted in the stir zone.

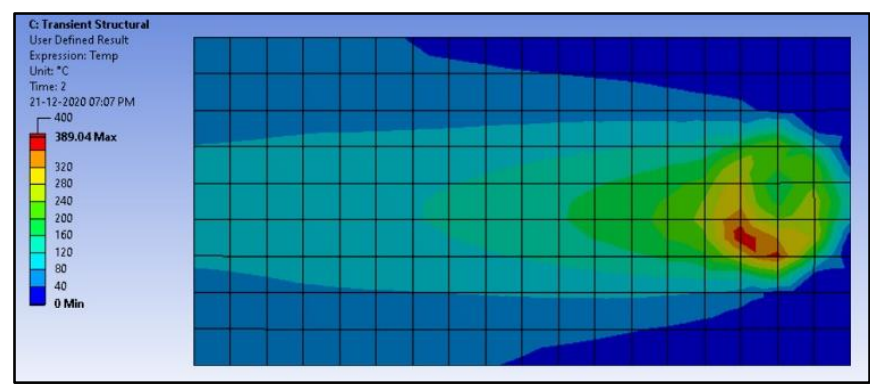

Figure 7. Experimental analysis 2 temperature results

\subsection{Translational speed}

The translational speed of the tool shifts the plasticized material from the initial position to the rear part of the workpiece. A substantial increase in the temperature value was observed on decreasing the translational speed of the tool from $60 \mathrm{~mm} / \mathrm{s}$ (Figure 6) to $40 \mathrm{~mm} / \mathrm{s}$ (Figure 8) with a subtle increase in the overall heated area of the workpiece surface. A maximum temperature of $194.61{ }^{\circ} \mathrm{C}$ was noted in the stir zone.

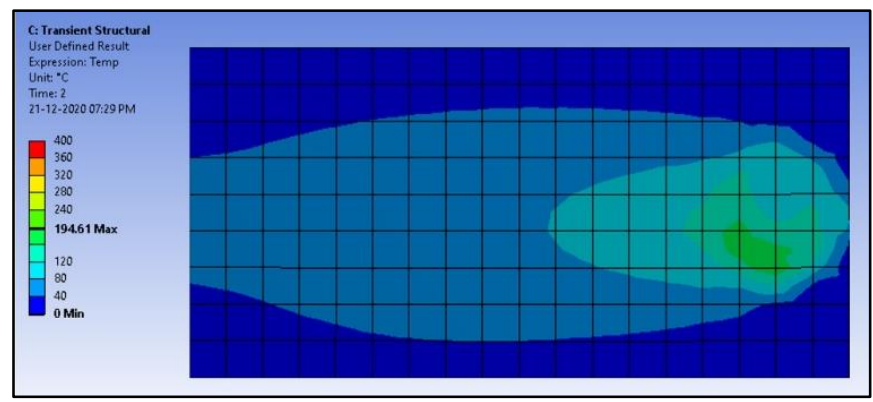

Figure 8. Experimental analysis 3 temperature results

\subsection{Plunge depth}

A rise in the depth of the plunge reduces mechanical prosperities and contributes to a faulty weld [14]. By raising the plunge depth from $0.2 \mathrm{~mm}$ (Figure 6) to $0.5 \mathrm{~mm}$ (Figure 9), a rise in the temperature value and a raise in the total heating area of the workpiece surface was observed. A maximum temperature of $328.8^{\circ} \mathrm{C}$ was noted in the stir zone. 


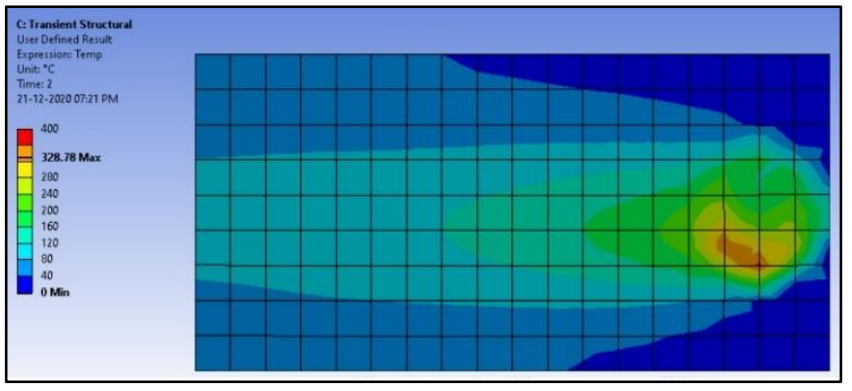

Figure 9. Experimental analysis 4 temperature results

\section{ANALYSIS OF STRESS DISTRIBUTION}

The difference in the frictional stress distribution result was studied, for the 4 considered experimental analysis. The highest value of frictional stress was observed in experiment 3 , that had a higher value of tool traverse speed. The frictional stress is found to have a uniform value throughout the contact surface. Frictional stress increases proportionally to the relative velocity w.r.t. the surface of the tool in contact with the workpiece. The values of maximum frictional stress achieved in the experimental analysis have been discussed below in Table 2 .

Table 2. Frictional stress results

\begin{tabular}{cc}
\hline Experiment No. & Maximum Value of Frictional Stress \\
\hline 1. & $42.5 \mathrm{MPa}$ \\
2. & $72.1 \mathrm{MPa}$ \\
3. & $43.5 \mathrm{MPa}$ \\
4. & $99 \mathrm{MPa}$ \\
\hline
\end{tabular}

\section{ANALYSIS OF TEMPERATURE DISTRIBUTION}

The difference in the temperature distribution results (along the thickness of the workpiece) were studied for the 4 considered experimental analysis. The highest value of temperature $\left(389.04^{\circ} \mathrm{C}\right)$ was observed in the experimental analysis 2 . The area associated with the heat-affected zone increased with an increase in the tool rotational speed. The surface at the top of the workpiece that is in direct contact with the tool is subjected to a higher level of distortion, hence the temperature is highest at the topmost surface [53]. The temperature gradually decreases as we go away from the contact point of tool and surface.

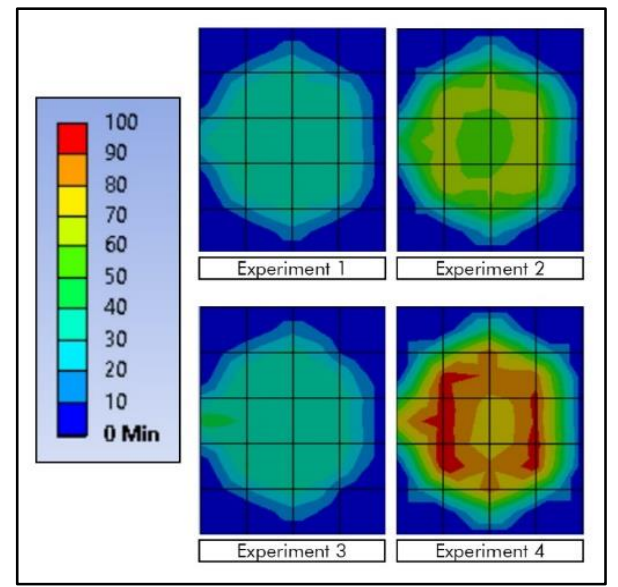

Figure 10. Frictional stress distribution results (on the surface)

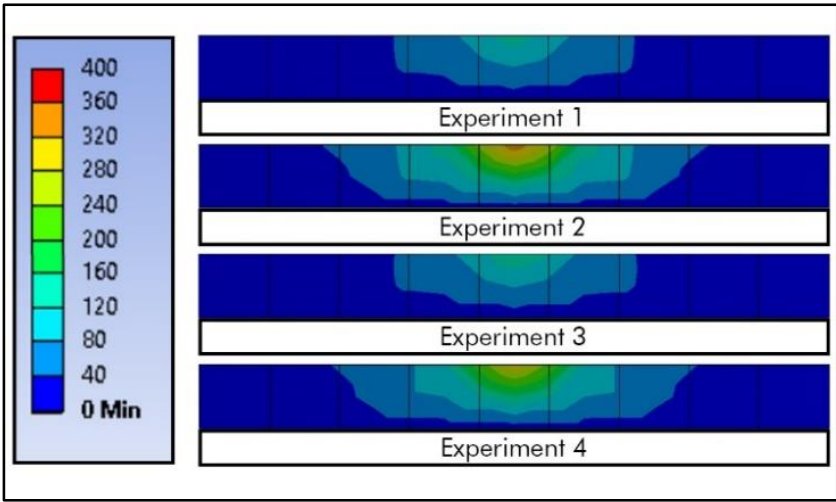

Figure 11. Temperature distribution results

\section{CONCLUSIONS}

(1) No variation in structure is observed even after multiple passes but the homogenisation of the microstructure is still achieved.

(2) The variation in temperature distribution due to the direction of tool rotation, can be seen throughout the surface.

(3) Numerical analysis of the process using ANSYS helps to accurately predict the temperature distribution in the processing region w.r.t a change in tool translational speed, tool rotational speed and tool plunge depth.

(4) The numerical analysis of the process is not sufficient to predict the mechanical properties of the processed material but helps to calculate a range of appropriate process parameter values that can help achieve the desired temperature range during the friction stir process.

\section{REFERENCES}

[1] Thomas, W.M., Nicholas, E.D., Needham, J.C., Murch, M.G., Temple-Smith, P., Dawes, C.J. (1995). U.S. Patent No. 5,460,317. Washington, DC: U.S. Patent and Trademark Office.

[2] Sato, Y.S., Kokawa, H., Enomoto, M., Jogan, S. (1999). Microstructural evolution of 6063 aluminum during friction-stir welding. Metallurgical and Materials $\begin{array}{lll}\text { Transactions } & \text { A, } & \text { 30(9): }\end{array}$ https://doi.org/10.1007/s11661-999-0251-1

[3] Murr, L.E., Flores, R.D., Flores, O.V., McClure, J.C., Liu, G., Brown, D. (1998). Friction-stir welding: Microstructural characterization. Material Research Innovations, 1(4): 211-223. https://doi.org/10.1007/s100190050043

[4] Rhodes, C.G., Mahoney, M.W., Bingel, W.H., Spurling, R.A., Bampton, C.C. (1997). Effects of friction stir welding on microstructure of 7075 aluminum. Scripta materialia, 36(1): 69-75. https://doi.org/10.1016/S13596462(96)00344-2

[5] Liu, G., Murr, L.E., Niou, C.S., McClure, J.C., Vega, F.R. (1997). Microstructural aspects of the friction-stir welding of 6061-T6 aluminum. Scripta Materialia, 37(3): 355-361. https://doi.org/10.1016/S1359-6462(97)000936

[6] Swarnkar, A., Kumar, R., Suri, A., Saha, A. (2016). A review on Friction Stir Welding: An environment friendly welding technique. In 2016 IEEE Region 10 
Humanitarian Technology Conference (R10-HTC) IEEE, 1-4. https://doi.org/10.1109/R10-HTC.2016.7906807

[7] Guerra, M., Schmidt, C., McClure, J.C., Murr, L.E., Nunes, A.C. (2002). Flow patterns during friction stir welding. Materials Characterization, 49(2): 95-101. https://doi.org/10.1016/S1044-5803(02)00362-5

[8] Storjohann, D., Barabash, O.M., David, S.A., Sklad, P.S., Bloom, E.E., Babu, S.S. (2005). Fusion and friction stir welding of aluminum-metal-matrix composites. Metallurgical and Materials Transactions A, 36(11): 3237-3247. https://doi.org/10.1007/s11661-005-0093-4

[9] Lee, W.B., Yeon, Y.M., Jung, S.B. (2003). The improvement of mechanical properties of friction-stirwelded A356 Al alloy. Materials Science and Engineering: $\quad$ A, $\quad 355(1-2)$ : 154-159. https://doi.org/10.1016/S0921-5093(03)00053-4

[10] Pashazadeh, H., Teimournezhad, J., Masoumi, A. (2014). Numerical investigation on the mechanical, thermal, metallurgical and material flow characteristics in friction stir welding of copper sheets with experimental verification. Materials \& Design, 55: 619-632. https://doi.org/10.1016/j.matdes.2013.09.028

[11] Ma, Z.Y. (2008). Friction stir processing technology: a review. Metallurgical and materials Transactions A, 39(3): 642-658. https://doi.org/10.1007/s11661-0079459-0

[12] Srivastava, A.K., Maurya, N.K., Maurya, M., Dwivedi, S.P., Saxena, A. (2020). Effect of multiple passes on microstructural and mechanical properties of surface composite Al 2024/SiC produced by friction stir processing. Annales de Chimie-Science des Matériaux, 44(6): 421-426. https://doi.org/10.18280/acsm.440608

[13] Maurya, M., Kumar, S., Maurya, N.K. (2020). Composites prepared via friction stir processing technique: A review. Revue des Composites et des Matériaux Avancés-Journal of Composite and Advanced Materials, 30(3-4):

143-151. https://doi.org/10.18280/rcma.303-404

[14] Dwivedi, S.P., Srivastava, A.K., Maurya, N.K., Sahu, R. (2020). Microstructure and mechanical behaviour of $\mathrm{Al} / \mathrm{SiC} /$ Agro-Waste RHA hybrid metal matrix composite. Revue des Composites et des Matériaux Avancés-Journal of Composite and Advanced Materials, 30(1): 43-47 https://doi.org/10.18280/rcma.300107

[15] Chen, Y., Ding, H., Li, J., Cai, Z., Zhao, J., Yang, W. (2016). Influence of multi-pass friction stir processing on the microstructure and mechanical properties of Al-5083 alloy. Materials Science and Engineering: A, 650: 281289. http://dx.doi.org/10.1016/j.msea.2015.10.057

[16] Mishra, R.S., Ma, Z.Y., Charit, I. (2003). Friction stir processing: a novel technique for fabrication of surface composite. Materials Science and Engineering: A, 341(12): 307-310. https://doi.org/10.1016/S0921 5093(02)00199-5

[17] Węglowski, M.S. (2018). Friction stir processing — state of the art. Archives of civil and Mechanical Engineering, 18: 114-129. https://doi.org/10.1016/j.acme.2017.06.002

[18] Patel, V.V., Badheka, V., Kumar, A. (2016). Friction stir processing as a novel technique to achieve superplasticity in aluminum alloys: process variables, variants, and applications. Metallography, Microstructure, and Analysis, 5(4): 278-293. https://doi.org/10.1007/s13632-016-0285-X

[19] Ma, Z.Y., Mishra, R.S., Mahoney, M.W. (2002).
Superplastic deformation behaviour of friction stir processed 7075Al alloy. Acta Materialia, 50(17): 44194430. https://doi.org/10.1016/S1359-6454(02)00278-1

[20] Mishra, R.S., Ma, Z.Y. (2005). Friction stir welding and processing. Materials Science and Engineering: R: reports, 50(1-2): 1-78. https://doi.org/10.1016/j.mser.2005.07.001

[21] Li, K., Liu, X., Zhao, Y. (2019). Research status and prospect of friction stir processing technology. Coatings, 9(2): 129. https://doi.org/10.3390/coatings9020129

[22] Darras, B.M., Omar, M.A., Khraisheh, M.K. (2007). Experimental thermal analysis of friction stir processing. In Materials science forum. Trans Tech Publications Ltd, 539: 3801-3806. https://doi.org/10.4028/www.scientific.net/MSF.539543.3801

[23] Sidhu, M.S., Chatha, S.S. (2012). Friction stir weldingprocess and its variables: A review. International Journal of Emerging Technology and Advanced Engineering, 2(12): 275-279.

[24] Carlone, P., Palazzo, G.S. (2013). Influence of process parameters on microstructure and mechanical properties in AA2024-T3 friction stir welding. Metallography, Microstructure, and Analysis, 2(4): 213-222. https://doi.org/10.1007/s13632-013-0078-4

[25] Pasebani, S., Charit, I., Mishra, R.S. (2015). Effect of tool rotation rate on constituent particles in a friction stir processed 2024Al alloy. Materials Letters, 160: 64-67. https://doi.org/10.1016/j.matlet.2015.07.074

[26] Nascimento, F., Santos, T., Vilaça, P., Miranda, R.M., Quintino, L. (2009). Microstructural modification and ductility enhancement of surfaces modified by FSP in aluminium alloys. Materials Science and Engineering: A, 506(1-2):

$16-22$ https://doi.org/10.1016/j.msea.2009.01.008

[27] Pashazadeh, H., Teimournezhad, J., Masoumi, A. (2014). Numerical investigation on the mechanical, thermal, metallurgical and material flow characteristics in friction stir welding of copper sheets with experimental verification. Materials \& Design, 55: 619-632. https://doi.org/10.1016/j.matdes.2013.09.028

[28] Ramezani, N.M., Davoodi, B., Aberoumand, M., Hajideh, M.R. (2019). Assessment of tool wear and mechanical properties of Al 7075 nanocomposite in friction stir processing (FSP). Journal of the Brazilian Society of Mechanical Sciences and Engineering, 41(4): 182. https://doi.org/10.1007/s40430-019-1683-1

[29] Abbasi, M., Bagheri, B., Keivani, R. (2015). Thermal analysis of friction stir welding process and investigation into affective parameters using simulation. Journal of Mechanical Science and Technology, 29(2): 861-866. https://doi.org/10.1007/s12206-015-0149-3

[30] Vigneshkumar, M., Padmanaban, G., Balasubramanian, V. (2019). Influence of tool tilt angle on the formation of friction stir processing zone in cast magnesium alloy ZK60/SiCp surface composites. Metallography, Microstructure, and Analysis, 8(1): 58-66. https://doi.org/10.1007/s13632-018-0507-5

[31] Zhao, Y.Q., Liu, H.J., Chen, S.X., Lin, Z., Hou, J.C. (2014). Effects of sleeve plunge depth on microstructures and mechanical properties of friction spot welded alclad 7B04-T74 aluminum alloy. Materials \& Design (19802015) 62 , 40-46. https://doi.org/10.1016/j.matdes.2014.05.012 
[32] Chaudhary, A., Dev, A.K., Goel, A., Butola, R., Ranganath, M.S. (2018). The mechanical properties of different alloys in friction stir processing: a review. Materials Today: Proceedings, 5(2): 5553-5562. https://doi.org/10.1016/j.matpr.2017.12.146

[33] Gope, P.C., Kumar, H., Purohit, H., Dayal, M. (2019). S$\mathrm{N}$ curves for fatigue life estimation of friction stir welded 19501 aluminum alloy T-joint. Proceedings of the Institution of Mechanical Engineers, Part C: Journal of Mechanical Engineering Science, 233(2): 664-674. https://doi.org/10.1177/0954406218760056

[34] Su, J.Q., Nelson, T.W., Sterling, C.J. (2005). Microstructure evolution during FSW/FSP of high strength aluminum alloys. Materials Science and Engineering: A, 405(1-2): 277-286. https://doi.org/10.1016/j.msea.2005.06.009

[35] Butola, R., Ranganath, M.S., Murtaza, Q. (2019). Fabrication and optimization of AA7075 matrix surface composites using Taguchi technique via friction stir processing (FSP). Engineering Research Express, 1(2): 025015.

[36] Ma, Z.Y., Sharma, S.R., Mishra, R.S. (2006). Effect of friction stir processing on the microstructure of cast A356 aluminum. Materials Science and Engineering: A, 433(1-2): 269-278. https://doi.org/10.1016/j.msea.2006.06.099

[37] Bauri, R., Yadav, D., Suhas, G. (2011). Effect of friction stir processing (FSP) on microstructure and properties of Al-TiC in situ composite. Materials Science and Engineering: A, 528(13-14): 4732-4739. https://doi.org/10.1016/j.msea.2011.02.085

[38] Sharma, V., Prakash, U., Kumar, B.M. (2015). Surface composites by friction stir processing: A review. Journal of Materials Processing Technology, 224: 117-134. https://doi.org/10.1016/j.jmatprotec.2015.04.019

[39] Azizieh, M., Mazaheri, M., Balak, Z., Kafashan, H., Kim, H.S. (2018). Fabrication of $\mathrm{Mg} / \mathrm{Al} 12 \mathrm{Mg} 17$ in-situ surface nanocomposite via friction stir processing. Materials Science and Engineering: A, 712: 655-662. https://doi.org/10.1016/j.msea.2017.12.030

[40] Zahmatkesh, B., Enayati, M.H. (2010). A novel approach for development of surface nanocomposite by friction stir processing. Materials Science and Engineering: A, 527(24-25):

6734-6740. https://doi.org/10.1016/j.msea.2010.07.024

[41] Sharma, A., Sharma, V.M., Mewar, S., Pal, S.K., Paul, J. (2018). Friction stir processing of Al6061-SiC-graphite hybrid surface composites. Materials and Manufacturing Processes, 33(7): 795-804 https://doi.org/10.1080/10426914.2017.1401726

[42] Singh, S., Pal, K. (2017). Influence of surface morphology and UFG on damping and mechanical properties of composite reinforced with spinel $\mathrm{MgAl} 2 \mathrm{O} 4-\mathrm{SiC}$ core-shell microcomposites. Materials Characterization, 123: 244-255. https://doi.org/10.1016/j.matchar.2016.11.042

[43] Butola, R., Tyagi, L., Kem, L., Ranganath, M.S.,
Murtaza, Q. (2020). Mechanical and wear properties of aluminium alloy composites: A review. Manufacturing Engineering, 369-391. https://doi.org/10.1007/978-98115-4619-8_28

[44] Butola, R., Murtaza, Q., Singari, R.M. (2020). Formation of self-assembled monolayer and characterization of AA7075-T6/B4C nano-ceramic surface composite using friction stir processing. Surface Topography: Metrology and Properties, 8(2): 025030.

[45] Tyagi, L., Butola, R., Jha, A.K. (2020). Mechanical and tribological properties of AA7075-T6 metal matrix composite reinforced with ceramic particles and aloevera ash via Friction stir processing. Materials Research Express, 7(6): 066526.

[46] Butola, R., Murtaza, Q., Singari, R.M. (2019). CNC turning and simulation of residual stress measurement on H13 tool steel. In Advances in Computational Methods in Manufacturing, Springer, Singapore, 337-348.

[47] Vaira Vignesh, R., Padmanaban, R., Datta, M. (2018). Influence of FSP on the microstructure, microhardness, intergranular corrosion susceptibility and wear resistance of AA5083 alloy. Tribology-Materials, Surfaces \& Interfaces, $\quad 12(3)$ : 157-169. https://doi.org/10.1080/17515831.2018.1483295

[48] Yazdipour, A., Dehghani, K. (2009). Modeling the microstructural evolution and effect of cooling rate on the nanograins formed during the friction stir processing of Al5083. Materxials Science and Engineering: A, 527(1-2):

192-197. https://doi.org/10.1016/j.msea.2009.08.040

[49] Chen, Y., Ding, H., Li, J., Cai, Z., Zhao, J., Yang, W. (2016). Influence of multi-pass friction stir processing on the microstructure and mechanical properties of Al-5083 alloy. Materials Science and Engineering: A, 650: 281289. https://doi.org/10.1016/j.msea.2015.10.057

[50] Bagheri, B., Abbasi, M. (2019). Analysis of microstructure and mechanical properties of friction stir vibration welded (FSVW) 5083 aluminum alloy joints: Experimental and simulation. Journal of Welding and Joining, 37(3): 243-253. https://doi.org/10.5781/JWJ.2019.37.3.8

[51] Bagheri, B., Rizi, A.A.M., Abbasi, M., Givi, M. (2019). Friction stir spot vibration welding: improving the microstructure and mechanical properties of Al5083 joint. Metallography, Microstructure, and Analysis, 8(5): 713725. https://doi.org/10.1007/s13632-019-00563-y

[52] Meyghani, B., Awang, M.B., Emamian, S.S., Mohd Nor, M.K.B., Pedapati, S.R. (2017). A comparison of different finite element methods in the thermal analysis of friction stir welding (FSW). Metals, 7(10): 450. https://doi.org/10.3390/met7100450

[53] Asadi, P., Mahdavinejad, R.A., Tutunchilar, S. (2011). Simulation and experimental investigation of FSP of AZ91 magnesium alloy. Materials Science and Engineering: A, 528(21): 6469-6477. https://doi.org/10.1016/j.msea.2011.05.035 